Article

\title{
Cesium Inhibits Plant Growth through Jasmonate Signaling in Arabidopsis thaliana
}

\author{
Eri Adams, Parisa Abdollahi and Ryoung Shin * \\ RIKEN Plant Science Center, 1-7-22 Suehiro-cho, Tsurumi-ku, Yokohama, Kanagawa 230-0045, \\ Japan; E-Mails: eriadams@psc.riken.jp (E.A.); parisa@psc.riken.jp (P.A.) \\ * Author to whom correspondence should be addressed; E-Mail: rshin@psc.riken.jp; \\ Tel.: +81-45-503-9577; Fax: +81-45-503-9650.
}

Received: 25 December 2012; in revised form: 25 January 2013 / Accepted: 6 February 2013 / Published: 25 February 2013

\begin{abstract}
It has been suggested that cesium is absorbed from the soil through potassium uptake machineries in plants; however, not much is known about perception mechanism and downstream response. Here, we report that the jasmonate pathway is required in plant response to cesium. Jasmonate biosynthesis mutant aos and jasmonate-insensitive mutant coil-16 show clear resistance to root growth inhibition caused by cesium. However, the potassium and cesium contents in these mutants are comparable to wild-type plants, indicating that jasmonate biosynthesis and signaling are not involved in cesium uptake, but involved in cesium perception. Cesium induces expression of a high-affinity potassium transporter gene $H A K 5$ and reduces potassium content in the plant body, suggesting a competitive nature of potassium and cesium uptake in plants. It has also been found that cesium-induced HAK5 expression is antagonized by exogenous application of methyl-jasmonate. Taken together, it has been indicated that cesium inhibits plant growth via induction of the jasmonate pathway and likely modifies potassium uptake machineries.
\end{abstract}

Keywords: cesium; potassium; Arabidopsis thaliana; jasmonate; HAK5

\section{Introduction}

Cesium $\left(\mathrm{Cs}^{+}\right)$is a Group I alkali metal, which exists naturally at very low concentrations in the soil. $\mathrm{Cs}^{+}$has no known beneficial function in plants; however, it can, at high concentrations, cause toxicity, observed as growth inhibition (reviewed in [1]). Thus far, $\mathrm{Cs}^{+}$uptake and response in plants have not 
been thoroughly studied. However, the accident at the Fukushima nuclear power plant following the disaster in 2011 in Japan highlighted the importance of understanding the mechanism of cesium uptake in plants to improve phytoremediation efficiency for radiocesium. Radiocesium, ${ }^{134} \mathrm{Cs}$ and ${ }^{137} \mathrm{Cs}$, produced from anthropogenic sources are of environmental and health concerns, since they are rapidly incorporated into the food chain, emit $\beta$ and $\gamma$ radiation and have relatively long half-lives (reviewed in [1]). The potential of plants to decontaminate radiocesium from soil was also focused after the accident in Chernobyl [2,3]. Earlier studies have suggested that $\mathrm{Cs}^{+}$may be absorbed by plants in a competitive fashion with potassium $\left(\mathrm{K}^{+}\right)$, which belongs to the same alkali metal group and shares similar chemical properties with $\mathrm{Cs}^{+}$. The first report that plants accumulate $\mathrm{Cs}^{+}$through the same uptake mechanism as $\mathrm{K}^{+}$was published as early as 1941 [4], and many other studies reinforced this view (reviewed in [1]). A theoretical modeling predicted that voltage-insensitive cation channels (VICCs) predominantly mediate $\mathrm{Cs}^{+}$uptake under the $\mathrm{K}^{+}$sufficient conditions and $\mathrm{K}^{+}$uptake permeases (KUPs) significantly contribute under the $\mathrm{K}^{+}$deficient conditions [1]. In Arabidopsis thaliana, some members of cyclic nucleotide gated channels (CNGCs), which belong to VICCs, such as CNGC1, CNGC2, CNGC4 and CNGC10, were predicted to form $\mathrm{K}^{+}$channels and, thus, suggested as being involved in $\mathrm{Cs}^{+}$uptake, also [5-8].

The first $\mathrm{K}^{+}$channel identified in plants is KAT1 from Arabidopsis, which functions at high $\mathrm{K}^{+}$ concentrations as a voltage-dependent, low-affinity inward rectifying channel [9]. The major $\mathrm{K}^{+}$ channel functioning in the roots of Arabidopsis under the $\mathrm{K}^{+}$sufficient conditions is assumed to be AKT1 [10]. However, the contribution of these channels to $\mathrm{Cs}^{+}$uptake is small or negligible [9,11]. In response to $\mathrm{K}^{+}$deficiency, expression of high-affinity $\mathrm{K}^{+}$transporters, members of the KUP family, are induced, such as high affinity $\mathrm{K}^{+}$transporter5 (HAK5) and KUP3 [12,13]. HAK5 has been reported to be involved in $\mathrm{Cs}^{+}$uptake in planta, consequently resulting in higher $\mathrm{Cs}^{+}$accumulation under the $\mathrm{K}^{+}$ deficient conditions [12]. Another $\mathrm{K}^{+}$transporter, KUP9, from Arabidopsis was also shown to transport $\mathrm{Cs}^{+}$when expressed in a $\mathrm{K}^{+}$transport-deficient mutant of Escherichia coli [14].

There have been a few reports pointing out interaction between $\mathrm{K}^{+}$deficiency response and phytohormone signaling. Expression of ethylene biosynthesis genes and ethylene production are reported to be induced in response to $\mathrm{K}^{+}$deficiency and, subsequently, activate reactive oxygen species production [15]. Expression of jasmonate (JA) biosynthesis genes is also induced in response to $\mathrm{K}^{+}$ deficiency and confers tolerance to insects [16-18]. Cytokinins, by contrast, decrease under the $\mathrm{K}^{+}$ deficient conditions and allow downstream response for adaptation to take place [19]. Auxin-related mutants were found to be impaired in $\mathrm{K}^{+}$deficiency-induced lateral root growth [20]. If $\mathrm{Cs}^{+}$were to cause similar effects as $\mathrm{K}^{+}$deficiency in plants, it is possible that $\mathrm{Cs}^{+}$response is regulated through phytohormone pathways.

In this study, JA biosynthesis and signaling were demonstrated to be required in plant response to $\mathrm{Cs}^{+}$. JAs are a class of phytohormone that are involved in various physiological processes, such as growth inhibition, fertility, senescence and defense against biotic and abiotic stresses [21]. JAs are biosynthesized from linolenic acid through a series of steps, including allene oxide synthase (AOS) [22], and recognized by a receptor complex which is composed of an E3 ubiquitin ligase, SCF (SKP1, CDC53p/CUL1 F-box protein) complex. An active form of JAs, the jasmonyl-isoleucine conjugate (JA-Ile), directly binds to the F-box protein in the receptor complex, CORONATINE INSENSITIVE1 (COI1), and $\mathrm{SCF}^{\mathrm{CO} 11}$ targets the negative regulators for proteolysis to activate 
downstream JA signaling in Arabidopsis [23-27]. Therefore, mutations in COII can render the plants insensitive to JAs [28,29].

Here, we investigated the relationship between JA biosynthesis/signaling and $\mathrm{Cs}^{+}$response in Arabidopsis in order to understand the fundamental mechanism of plant response to $\mathrm{Cs}^{+}$. Our studies revealed the induction of JA biosynthesis/signaling and consequent growth inhibition in response to $\mathrm{Cs}^{+}$. However, JA signaling was not apparently involved in $\mathrm{Cs}^{+}$uptake under the $\mathrm{K}^{+}$sufficient conditions. Meanwhile, induction of $H A K 5$ was demonstrated in response to $\mathrm{Cs}^{+}$, suggesting the involvement of $\mathrm{K}^{+}$uptake machineries in $\mathrm{Cs}^{+}$uptake. The possibility of JA signaling casting an antagonistic effect on $H A K 5$ expression was also implied. In this report, plant response to $\mathrm{Cs}^{+}$is dissected.

\section{Results}

\subsection{JA-Related Mutants Are Less Responsive to $\mathrm{Cs}^{+}$-Induced Growth Inhibition}

In order to understand the mechanism of $\mathrm{Cs}^{+}$response in plants, phytohormone-related mutants in Arabidopsis thaliana were tested on $0.5 \mathrm{mM} \mathrm{KCl}$ with or without $0.3 \mathrm{mM} \mathrm{CsCl}$. This condition was chosen as a "stringent condition" for monitoring strong $\mathrm{Cs}^{+}$resistance phenotype. In this condition, growth of Col-0 plants (wild-type) was severely retarded by the addition of $\mathrm{CsCl}$ (Figure 1A). However, a JA biosynthesis mutant aos [30,31] and a JA-insensitive mutant coil-16 [29] showed significantly less response to $\mathrm{Cs}^{+}$-induced root growth retardation $(p<0.001$, Figure 1). A mutant, which produces less bioactive JA-Ile and shows mild JA-insensitive phenotype, jasmonate resistant1 (jar 1-1) [32], also showed less response to $\mathrm{Cs}^{+}$in terms of root growth inhibition $(p<0.001$, Table $\mathrm{S} 1)$. Among them, the stronger phenotype of aos corresponds with the fact that the aos mutant is a knockout line [30]. The coil-16 and jarl-1 mutants are known to be "leaky" [29,33], and this might be why their resistance to $\mathrm{Cs}^{+}$was also compromised. Also, other phytohormone-related mutants were found to be less responsive to $\mathrm{Cs}^{+}$, such as an auxin-insensitive mutant, auxin resistant1 (aux 1-7) [34] $(p<0.001)$, and, to a lesser extent $(p<0.01)$, a trans-zeatin-type cytokinin biosynthesis quadruple mutant, isopentenyltransferase 1,3,5,7 (ipt1,3,5,7) [35] and a cytokinin-insensitive double mutant histidine kinase2;3 (ahk2;3) [36] (Table S1). An ethylene-insensitive mutant, ethylene insensitive2, (ein2-1) [37], but not ethylene response sensor1 (ers 1-1) [38], was marginally less responsive to $\mathrm{Cs}^{+}$ $(p<0.05$, Table S1). A GA-related DELLA double mutant, repressor of ga; gibberellic acid insensitive (rga-24;gai-t6) [39], showed increased growth \% in response to $\mathrm{Cs}^{+}$compared to its wild-type, Ler $(p<0.001$, Table S1). This could be due to the absence of growth inhibitor proteins in the mutant [39], enabling the resistance to $\mathrm{Cs}^{+}$-induced growth inhibition, but further analysis is required for confirmation. The relationship between $\mathrm{Cs}^{+}$response and JA signaling was further investigated.

\subsection{Resistance of JA-Related Mutants to $\mathrm{Cs}^{+}$Was Not Due to Less Uptake of Cs ${ }^{+}$}

JA-related mutants were found to be less responsive to $\mathrm{Cs}^{+}$-induced growth inhibition compared to wild-type. One explanation could be that JA-related mutants might be impaired in $\mathrm{Cs}^{+}$uptake. To test this possibility, $\mathrm{K}^{+}$and $\mathrm{Cs}^{+}$contents were measured in wild-type, aos and coil-16 treated with or without $0.3 \mathrm{mM} \mathrm{CsCl}$ under the $\mathrm{K}^{+}$sufficient condition $(1.75 \mathrm{mM} \mathrm{KCl})$ for seven days. Reduced $\mathrm{K}^{+}$ contents were observed upon $\mathrm{Cs}^{+}$treatment $(p<0.05$, Figure $2 \mathrm{~A})$. However, there was no statistically 
significant difference observed between wild-type and mutants for both $\mathrm{K}^{+}$and $\mathrm{Cs}^{+}$contents, regardless of $\mathrm{Cs}^{+}$treatment (Figure 2). This suggests that the JA pathway is not involved in the uptake of $\mathrm{Cs}^{+}$or $\mathrm{K}^{+}$in this condition. More $\mathrm{K}^{+}$and $\mathrm{Cs}^{+}$were accumulated per mg dry weight at the later stage of growth (day 12), but the pattern was maintained (Figure S1).

Figure 1. (A) Phenotype of Col-0 (wild type), aos and coil-16 grown on $0.5 \mathrm{mM} \mathrm{KCl}$ with or without $0.3 \mathrm{mM} \mathrm{CsCl}$ for seven days. (B) Primary root \% growth on $0.3 \mathrm{mM} \mathrm{CsCl}$ compared to the control condition. Primary root lengths of the seedlings treated with or without cesium were measured, and the \% growth was calculated for Col-0 (black bar), aos (crisscross bar) and coil-16 (white bar). Error bars indicate standard error $(n \geq 20)$. Statistically significant differences $(p<0.001)$ compared to Col- 0 are indicated as asterisks.

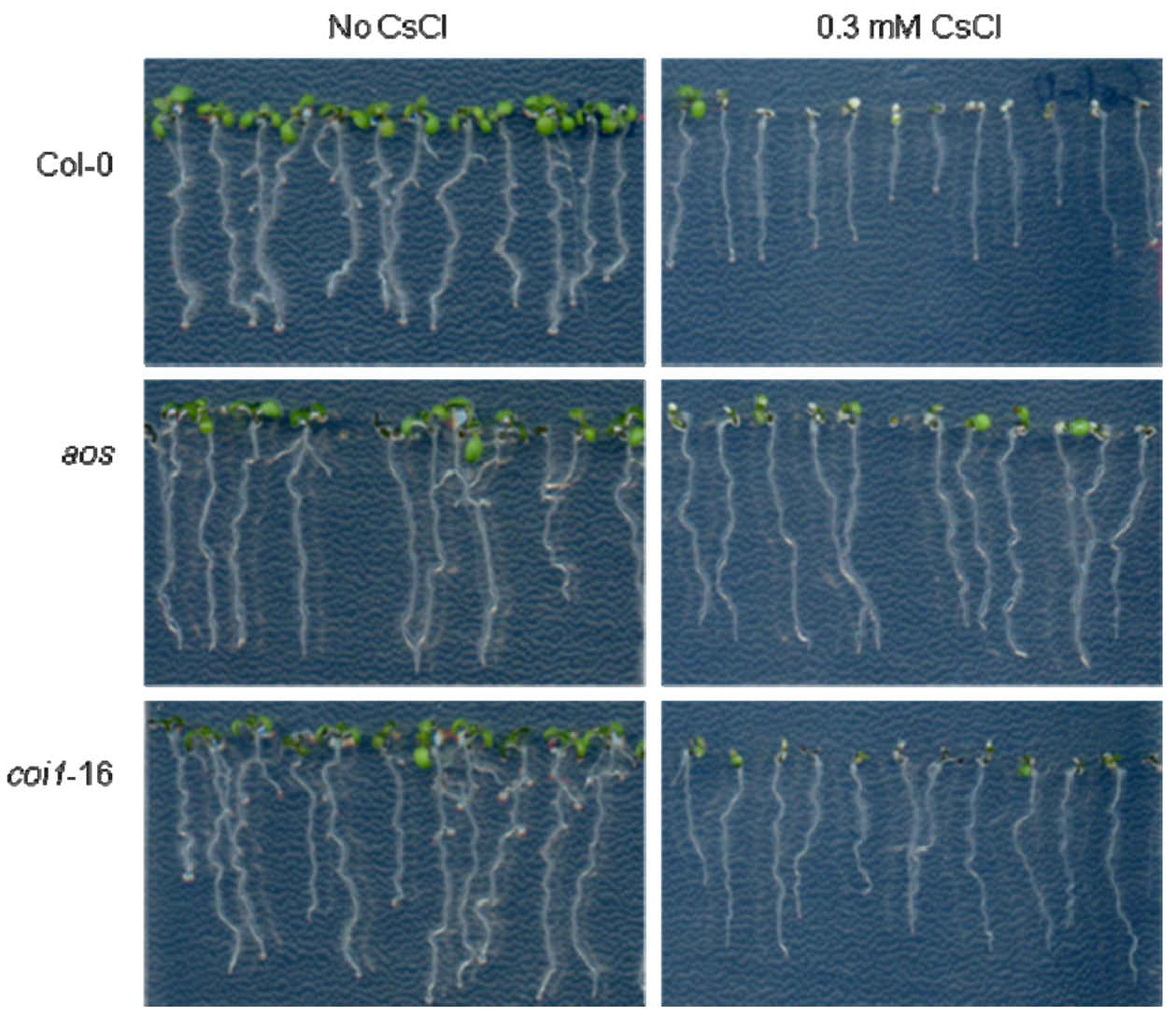

(A)

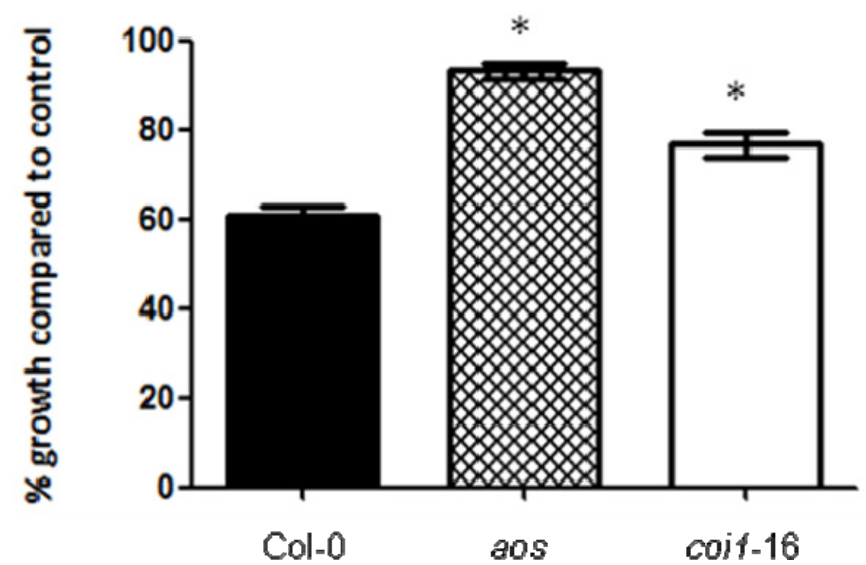

(B) 
Figure 2. (A) $\mathrm{K}^{+}$contents in Col-0, aos and coil-16 grown on $1.75 \mathrm{mM} \mathrm{KCl}$ with (white bars) or without (black bars) $0.3 \mathrm{mM} \mathrm{CsCl}$ for seven days. (B) $\mathrm{Cs}^{+}$contents in Col-0, aos and coil-16 grown on $1.75 \mathrm{mM} \mathrm{KCl}$ with (dotted bars) or without $0.3 \mathrm{mM} \mathrm{CsCl}$ for seven days. Error bars indicate standard error for four biological replicates. Each sample contained more than 15 seedlings. b.d.: below the detection limit. Alphabetical letters show statistical differences $(p<0.05)$.

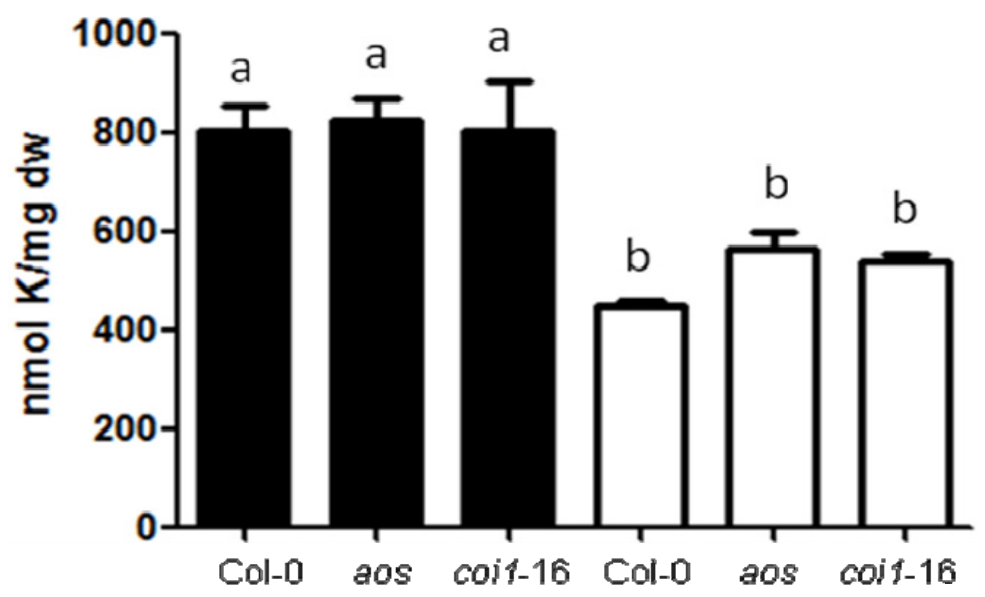

(A)

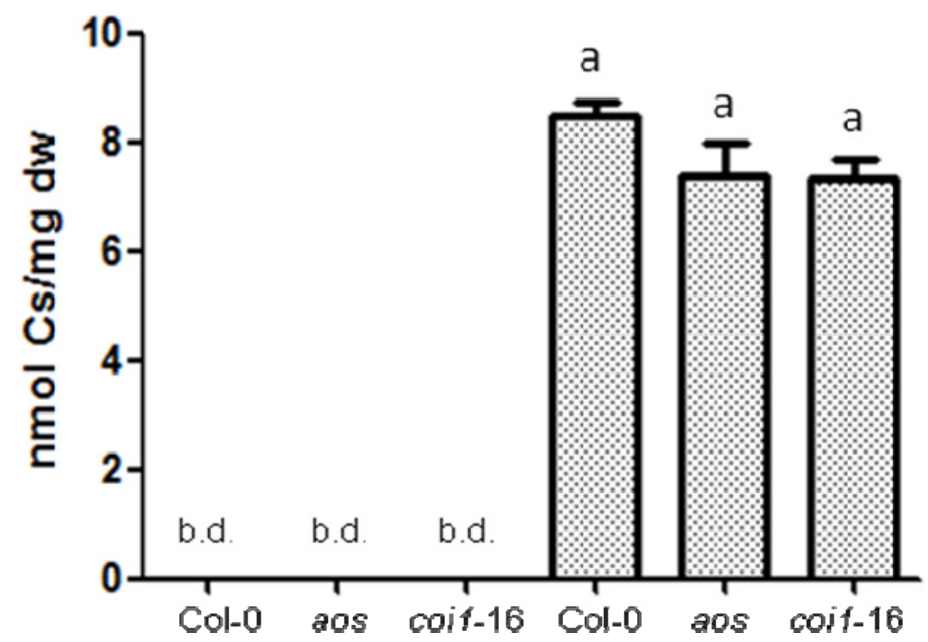

(B)

\section{3. $\mathrm{Cs}^{+}$Induces JA Signaling as well as HAK5 Expression}

To further analyze the interplay between $\mathrm{Cs}^{+}$perception and JA signaling, expression of the marker genes for JA signaling, PDF1.2 and VSP2 [40-42], was investigated in response to $\mathrm{Cs}^{+}$. Both PDF 1.2 and VSP2 levels were increased upon $\mathrm{Cs}^{+}$treatment under the $\mathrm{K}^{+}$sufficient condition, especially in the shoots $\left(p<0.05\right.$, Figure 3 ), suggesting the induction of the general JA pathway by $\mathrm{Cs}^{+}$. This induction was absent in the aos mutant (Figure S2). There was no additive effect of $\mathrm{Cs}^{+}$on methyl jasmonate (MeJA)-induced VSP2 expression (Figure 3).

It has been reported that high-affinity $\mathrm{K}^{+}$transporter, HAK5, is not only involved in $\mathrm{K}^{+}$uptake, but also in $\mathrm{Cs}^{+}$uptake [12]. The expression of HAK5 is sharply induced in response to $\mathrm{K}^{+}$deficiency [12], and there are some indications that $\mathrm{Cs}^{+}$may cause $\mathrm{K}^{+}$deficiency in plants. Therefore, we analyzed the 
transcript levels of $H A K 5$ in response to $\mathrm{Cs}^{+}$under the $\mathrm{K}^{+}$sufficient condition. Expression of $H A K 5$ was, indeed, induced in response to $\mathrm{Cs}^{+}$, and this induction also occurred in JA-related mutants, aos and coil-16 ( $p<0.05$, Figure 4$)$.

Figure 3. (A) Gene expression of PDF1.2 in Col-0 shoots and (B) roots, and (C) gene expression of VSP2 in Col-0 shoots and (D) roots, grown on $1.75 \mathrm{mM} \mathrm{KCl}$ with or without $0.3 \mathrm{mM} \mathrm{CsCl}$ and $2.5 \mathrm{mM}$ methyl jasmonate (MeJA) for 11 days. Values are $\log _{2}$ ratios relative to the control. Error bars indicate standard error for three technical replicates. Each sample contained more than 15 seedlings, and the experiment was repeated three times, one of which is presented. Alphabetical letters show statistical differences $(p<0.05)$.

PDF1.2 (shoot)

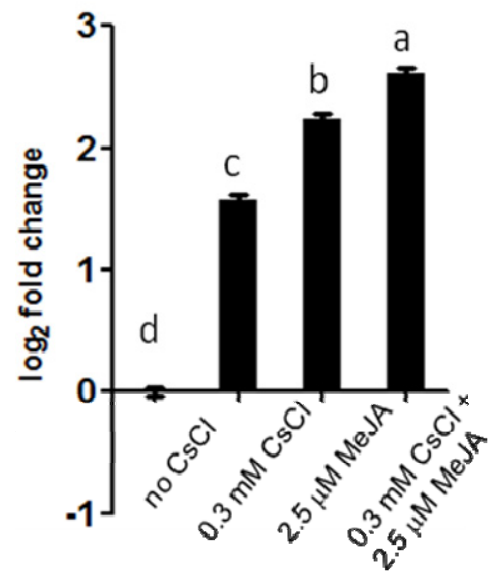

(A)

VSP2 (shoot)

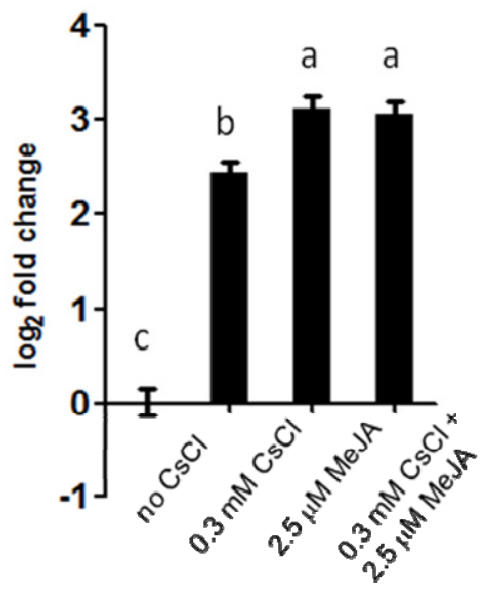

(C)
PDF1.2 (root)

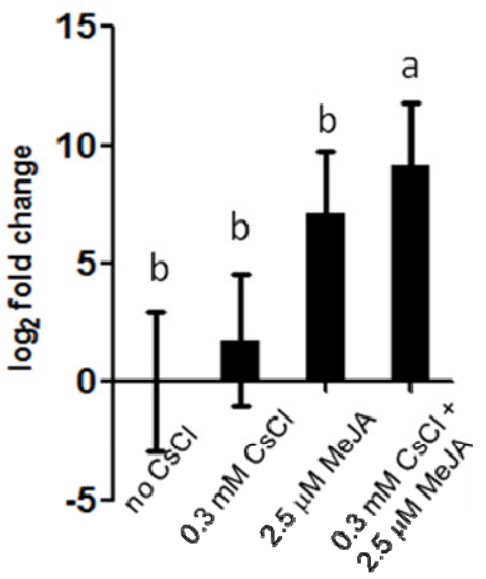

(B)

VSP2 (root)

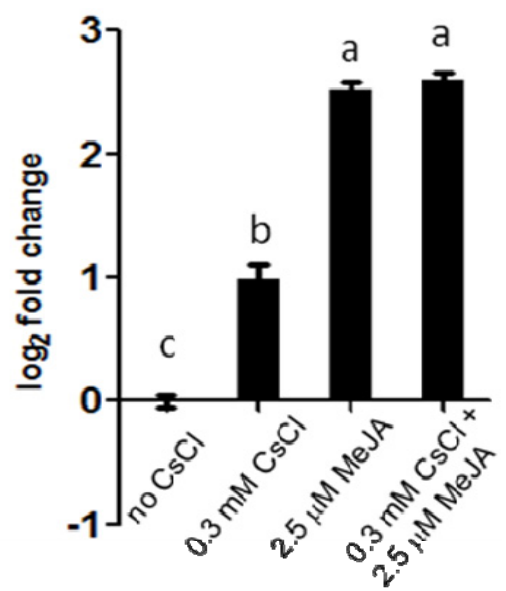

(D)

\subsection{JA Antagonizes $\mathrm{Cs}^{+}$-Induced HAK5 Expression}

Since $H A K 5$ was found to be induced in response to $\mathrm{Cs}^{+}$, spatial localization of HAK5 was investigated. Transgenic plants carrying the $H A K 5$ promoter fused to the luciferase reporter construct (HAK5 5 romoter::LUC) were used, and their activities are known to be induced in $\mathrm{K}^{+}$deficiency [15]. In this study, low levels of luciferase activity were visible at root tips of untreated plants under the $\mathrm{K}^{+}$ 
sufficient condition (Figure 5). Upon $\mathrm{Cs}^{+}$treatment, strong induction of luciferase activity was observed in the roots, and this induction was abolished by the addition of MeJA (Figure 5). The chemiluminescence intensity of these images and quantification of HAK5 transcripts in wild-type roots treated with $\mathrm{Cs}^{+}$and MeJA are shown in Table S2 and Figure S3, respectively. Chemiluminescence images of HAK5 promoter::LUC plants grown on $0.5 \mathrm{mM} \mathrm{KCl}$ with or without $\mathrm{Cs}^{+}$are also presented in Figure S4.

Figure 4. Gene expression of HAK5 in Col-0 (black bar), aos (crisscross bar) and coil-16 (white bar) grown on $1.75 \mathrm{mM} \mathrm{KCl}$ with or without $0.3 \mathrm{mM} \mathrm{CsCl}$ for seven days. Values are $\log _{2}$ ratios relative to the controls. Error bars indicate standard error for three technical replicates. Each sample contained more than 15 seedlings, and the experiment was repeated three times, one of which is presented. Statistically significant differences $(p<0.05)$ compared to each non-treated sample are indicated as asterisks.

\section{HAK5}

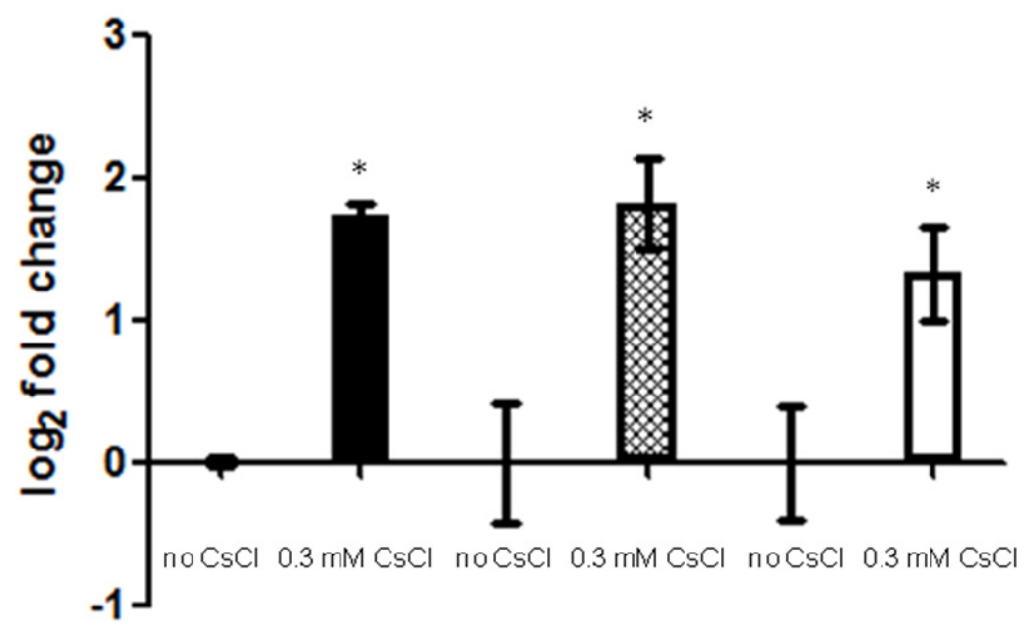

Figure 5. Chemiluminescence imaging of HAK5promoter::LUC plants grown on $1.75 \mathrm{mM} \mathrm{KCl}$ with or without $0.3 \mathrm{mM} \mathrm{CsCl}$ and $2.5 \mathrm{mM}$ MeJA for 11 days. Pseudo color represents the intensity of chemiluminescence.

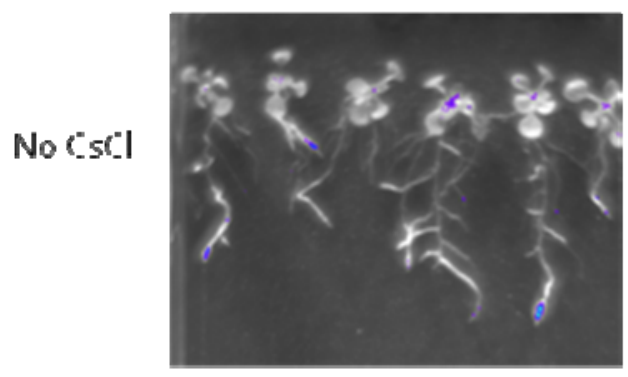

$0.3 \mathrm{mMCs}$
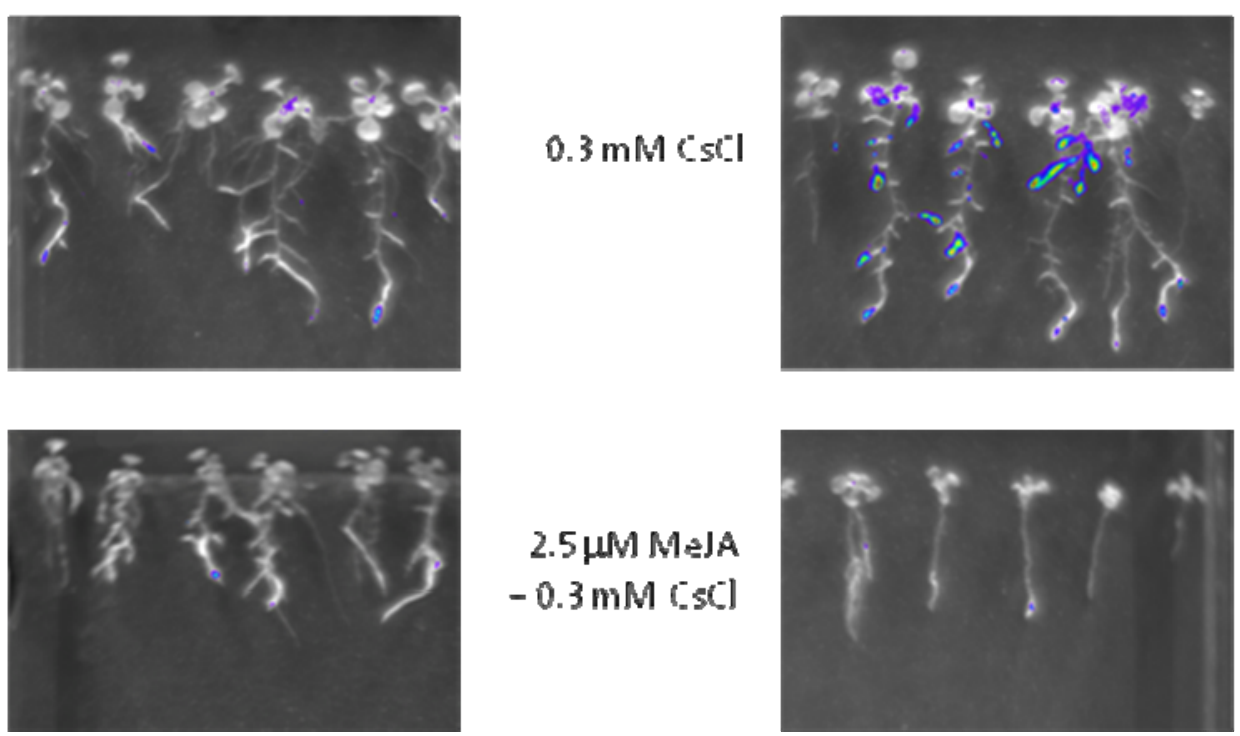

$2.5 \mu \mathrm{MM} \mathrm{MAA}$ $-0.3 \mathrm{mM}[\mathrm{sc}]$

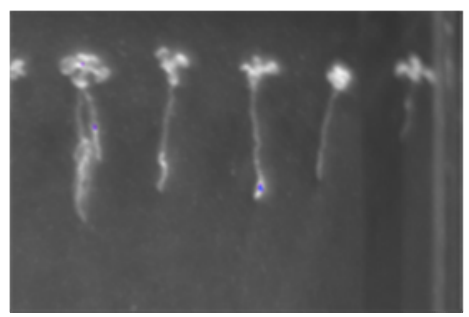




\section{Discussion}

$\mathrm{Cs}^{+}$has no known nutritional or other function in plants. Thus far, scarcely any knowledge has been gained on how plants absorb $\mathrm{Cs}^{+}$from the soil, how it is transported inside the plant body, and what is the plant response. However, an urgent need for improved phytoremediation methods for radioactive $\mathrm{Cs}^{+}$has urged scientists to better understand the mechanism of $\mathrm{Cs}^{+}$uptake, transport and perception in plants. In Arabidopsis, a possible mechanism for tolerance to heavy metals, such as arsenic, mercury and cadmium, has been reported [43,44], but whether the same tolerance mechanism applies for $\mathrm{Cs}^{+}$is not yet known. A T-DNA insertion mutant which is impaired in $\mathrm{Cs}^{+}$uptake has been isolated; however, the identity of the gene disturbed is not revealed [45].

The similarity of the nature between $\mathrm{Cs}^{+}$and $\mathrm{K}^{+}$and the involvement of phytohormone pathways in $\mathrm{K}^{+}$deficiency response provoked us to investigate the relationship between phytohormone pathways and $\mathrm{Cs}^{+}$response. For this purpose, various phytohormone-related mutants in Arabidopsis thaliana were analyzed for their response to $\mathrm{Cs}^{+}$. It has been reported that $\mathrm{K}^{+}$deficiency response is observed under $100 \mu \mathrm{M} \mathrm{K}^{+}$concentrations in Arabidopsis [12]. Therefore, we used the $0.5 \mathrm{mM} \mathrm{KCl}$ condition, which is well above the threshold for " $\mathrm{K}^{+}$deficient conditions", but lower than what is generally taken as " $\mathrm{K}^{+}$sufficient conditions" $(1.75 \mathrm{mM} \mathrm{KCl})$ [12], to create a "stringent condition" in selecting strong phenotype mutants for $\mathrm{Cs}^{+}$. Of those mutants tested, JA-related mutants, aos, coil-16 and jarl-1, showed strong resistance to $\mathrm{Cs}^{+}$-induced growth inhibition. Our data suggest that the JA pathway, and possibly some other phytohormone pathways, is involved in plant response to $\mathrm{Cs}^{+}$. This is the first report, as far as we are aware, to demonstrate the interaction between $\mathrm{Cs}^{+}$response and the JA pathway in plants. Some phytohormone pathways, including ethylene, auxin, cytokinin and JA, have been reported to be involved in response to $\mathrm{K}^{+}$deficiency [15-20]; therefore, in the future, it will be interesting to investigate the relationship of the $\mathrm{Cs}^{+}$-induced JA pathway with $\mathrm{K}^{+}$deficiency.

Although aos and coil-16 were less responsive to $\mathrm{Cs}^{+}$, this was not because they accumulated less $\mathrm{Cs}^{+} . \mathrm{Cs}^{+}$contents, as well as $\mathrm{K}^{+}$contents, were comparable to those of wild-type plants, suggesting that the JA pathway is involved, at least partly, in the perception of $\mathrm{Cs}^{+}$, not in uptake. Classic downstream marker genes of the JA pathway, PDF1.2 and VSP2, represent two distinct branches of the signaling pathway [40-42]. Under the $\mathrm{K}^{+}$sufficient condition, both of these marker genes were found to be increased in response to $\mathrm{Cs}^{+}$, especially in the aerial parts. This induction was not observed in the aos mutant, indicating that $\mathrm{Cs}^{+}$induces JA biosynthesis and downstream signaling.

It was also interesting to observe that $\mathrm{K}^{+}$contents were reduced upon $\mathrm{Cs}^{+}$treatment under the $\mathrm{K}^{+}$ sufficient condition. The competitive nature between $\mathrm{Cs}^{+}$and $\mathrm{K}^{+}$accumulation in Arabidopsis was demonstrated in a previous report [46]. Although $\mathrm{Cs}^{+}$has been used as a classic pharmacological inhibitor of $\mathrm{K}^{+}$channels [47], our findings might also indicate that $\mathrm{Cs}^{+}$could have been absorbed through the $\mathrm{K}^{+}$uptake mechanism in a competitive manner. There are a few reports that suggest the possibility of $\mathrm{K}^{+}$transporters/channels absorbing $\mathrm{Cs}^{+}$in plants, including a low-affinity inward-rectifying channel in Arabidopsis, KAT1 [9], a high-affinity $\mathrm{K}^{+}$transporter, HAK5 [12,48], and another $\mathrm{K}^{+}$ transporter, KUP9 [14]. In this study, we indicated that the transcript levels of HAK5 were increased in response to $\mathrm{Cs}^{+}$under the $\mathrm{K}^{+}$sufficient condition. The reporter construct study using HAK5 promoter::LUC showed that its promoter activity was particularly notable in the actively growing part of the roots, and this pattern was similar to that of the $\mathrm{K}^{+}$-starved plants [15]. These 
findings, together with the results from the $\mathrm{K}^{+} / \mathrm{Cs}^{+}$content study, agree with the hypothesis that $\mathrm{Cs}^{+}$is absorbed through $\mathrm{K}^{+}$uptake machinery in a competitive fashion.

JA treatment, on the other hand, was found to abolish $\mathrm{Cs}^{+}$-induced HAK5 expression in the reporter construct study, suggesting an antagonistic effect of JA on HAK5 expression. Since $\mathrm{Cs}^{+}$seemingly induces both JA biosynthesis/signaling and HAK5 expression, this antagonism may function as a negative feedback mechanism to fine-tune $\mathrm{Cs}^{+}$response in plants.

A summary of our findings on $\mathrm{Cs}^{+}$-induced growth inhibition and gene expression is shown as a model pathway in Figure 6. $\mathrm{Cs}^{+}$induces JA biosynthesis and the downstream signaling pathway in Arabidopsis. This is probably the major pathway for $\mathrm{Cs}^{+}$-induced growth inhibition of roots, since a mutant incapable of producing JAs hardly shows any reduction in root length in response to $\mathrm{Cs}^{+}$. In parallel, $\mathrm{Cs}^{+}$induces $H A K 5$, a reporter gene for $\mathrm{K}^{+}$deficiency [49]. Further studies are required to elucidate whether $\mathrm{Cs}^{+}$treatment causes $\mathrm{K}^{+}$deficiency to induce $H A K 5$ expression in plants. It will be interesting to test plant response to $\mathrm{Cs}^{+}$under various $\mathrm{K}^{+}$conditions, since plants are expected to exhibit different $\mathrm{K}^{+}$uptake mechanisms, according to $\mathrm{K}^{+}$availability. It was also indicated that the JA pathway might antagonize $H A K 5$ expression. The mechanism in which this antagonism occurs awaits elaboration; however, it is possible that one of APETALA2/Ethylene Response Factor (AP2/ERF) transcription factors induced by the JA signaling pathway binds to the GCC-box of the HAK5 promoter to regulate its expression. HAK5 has been reported to be regulated by an ERF/AP2 transcription factor, RAP2.11, in response to $\mathrm{K}^{+}$deficiency [50]. Meanwhile, JA-inducible AP2/ERFs are known to regulate expression of a series of GCC-box-containing genes, such as PDF1.2, through direct binding to the GCC-boxes of the promoter region [51-53]. Recently, involvement of cytokinin in $\mathrm{K}^{+}$ deficiency response and $H A K 5$ expression has been reported [19]. It will be also interesting to further investigate the involvement of biosynthesis and the signaling of cytokinin and other phytohormones in $\mathrm{Cs}^{+}$response in plants.

Here, we presented the first report that demonstrated the interplay between $\mathrm{Cs}^{+}$response and JA signaling in plants. It was also highlighted that $\mathrm{Cs}^{+}$uptake, $\mathrm{Cs}^{+}$-induced growth inhibition and gene expression were apparently regulated through different mechanisms. Elucidation of the fine balance between $\mathrm{K}^{+}$and $\mathrm{Cs}^{+}$to regulate plant response and growth is awaited.

\section{Experimental Section}

\subsection{Plant Material and Growth Conditions}

The Arabidopsis thaliana (L.) Heynh. accession Col-0 and Ler were used as wild-types. HAK5 promoter::LUC was developed in the lab [15]. aos [30,31], ein2-1 [37] and jar1-1 [32] are NASC stocks (Nottingham Arabidopsis Stock Centre, Loughborough, UK). coil-16 [29], ipt1,3,5,7 [35], ahk2;3 [36], ers 1-1 [38], aux1-7 [34] and rga-24;gai-t6 [39] were gifts from Dr. Turner, Dr. Kakimoto, Dr. Wen, Dr. Schachtman and Dr. Harberd. Seeds were surface-sterilized with $70 \%(v / v)$ ethanol and $0.05 \%(v / v)$ Triton X-100 and sown on media, indicated below. For the growth assay, media contained $0.5 \mathrm{mM} \mathrm{KCl}, 2 \mathrm{mM} \mathrm{Ca}\left(\mathrm{NO}_{3}\right)_{2}, 0.5 \mathrm{mM}$ phosphoric acid, $0.75 \mathrm{mM} \mathrm{MgSO}_{4}, 50 \mu \mathrm{M} \mathrm{H}_{3} \mathrm{BO}_{3}, 10 \mu \mathrm{M}$ $\mathrm{MnCl}, 2 \mu \mathrm{M} \mathrm{ZnSO}_{4}, 1.5 \mu \mathrm{M} \mathrm{CuSO}_{4}, 0.075 \mu \mathrm{M} \mathrm{NH}_{4} \mathrm{Mo}_{7} \mathrm{O}_{24}$ and $74 \mu \mathrm{M}$ Fe-EDTA, pH 5.8, with $\mathrm{Ca}(\mathrm{OH})_{2}, 1 \%(w / v)$ sucrose and $0.5 \%(w / v)$ SeaKem agarose (Cambrex, Rockland, ME, USA) 
supplemented with or without $0.3 \mathrm{mM} \mathrm{CsCl}$ and for the rest of the study, media contained $1.75 \mathrm{mM}$ $\mathrm{KCl}, 2 \mathrm{mM} \mathrm{Ca}\left(\mathrm{NO}_{3}\right)_{2}, 0.5 \mathrm{mM}$ phosphoric acid, $0.75 \mathrm{mM} \mathrm{MgSO}_{4}, 50 \mu \mathrm{M} \mathrm{H}_{3} \mathrm{BO}_{3}, 10 \mu \mathrm{M} \mathrm{MnCl}, 2 \mu \mathrm{M}$ $\mathrm{ZnSO}_{4}, 1.5 \mu \mathrm{M} \mathrm{CuSO}_{4}, 0.075 \mu \mathrm{M} \mathrm{NH}_{4} \mathrm{Mo}_{7} \mathrm{O}_{24}$ and $74 \mu \mathrm{M}$ Fe-EDTA, pH 5.8, with $\mathrm{Ca}(\mathrm{OH})_{2}, 1 \%(w / v)$ sucrose and $0.5 \%(w / v)$ SeaKem agarose (Cambrex) supplemented with or without $0.3 \mathrm{mM} \mathrm{CsCl}$ or $2.5 \mu \mathrm{M}$ MeJA. After stratifying for 3 to 4 days at $4{ }^{\circ} \mathrm{C}$, plants were placed in a vertical orientation in a growth cabinet at $22^{\circ} \mathrm{C}$ in a $16 \mathrm{~h} \mathrm{light} / 8 \mathrm{~h}$ dark photocycle with a light intensity of $70-90 \mu \mathrm{mol} / \mathrm{m}^{2} / \mathrm{sec}$.

Figure 6. Model pathway. $\mathrm{Cs}^{+}$induces the JA pathway and inhibits plant growth. $\mathrm{Cs}^{+}$also induces $H A K 5$ expression. Whether this expression is due to $\mathrm{Cs}^{+}$-induced $\mathrm{K}^{+}$deficiency or the direct effect of $\mathrm{Cs}^{+}$is not yet clear. An antagonistic effect of the JA pathway on HAK5 expression is also suggested.

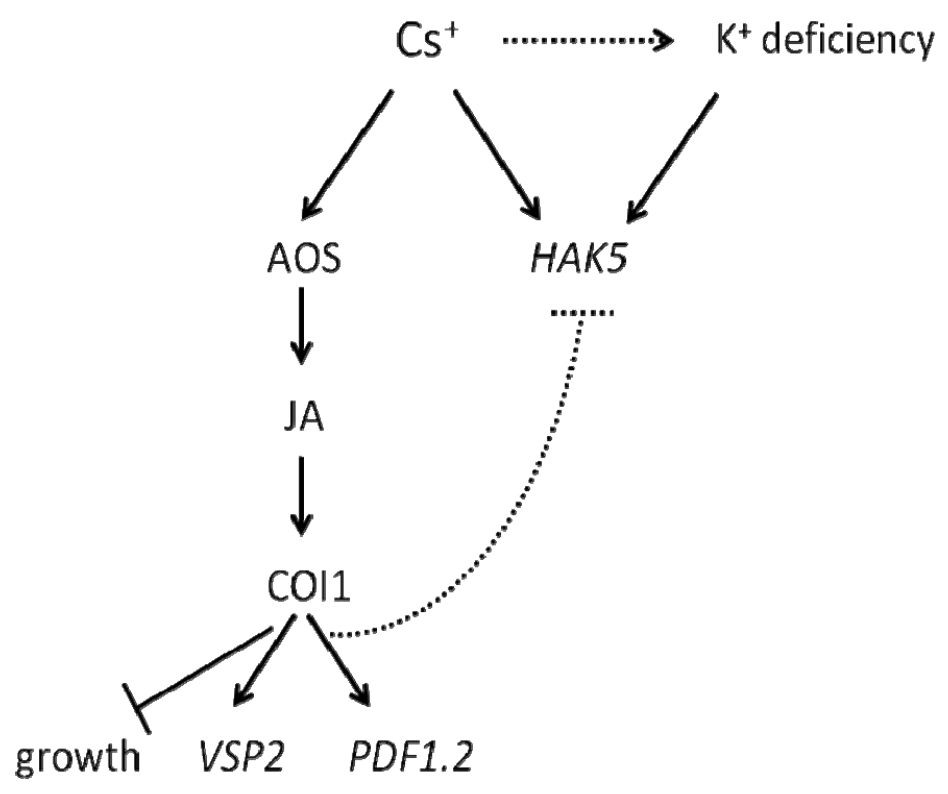

\subsection{Root Growth Assay}

Seedlings grown for 7 days were removed from media, and the root lengths were measured directly on a ruler wetted with $70 \%(v / v)$ glycerol. The relative $\%$ of root growth was calculated according to the formula, $y / x \times 100$, where $x$ was the average of root lengths of untreated seedlings and $y$ was the root lengths of each $\mathrm{Cs}^{+}$-treated seedling and was averaged. One-way ANOVA with Dunnett's multiple comparison posttest $(p<0.05$ ) was performed using Prism (GraphPad Software, La Jolla, CA, USA) to determine the statistical significance.

\subsection{Element Analysis}

Seedlings grown for 7 days were washed in Milli-Q water, dried on a piece of paper towel, placed in a paper envelope and dried in an oven at $65^{\circ} \mathrm{C}$ for 3-4 days. Approximately $2 \mathrm{mg}$ of dried samples were extracted in $1 \mathrm{~mL}$ of $60 \%(v / v) \mathrm{HNO}_{3}$ at $125^{\circ} \mathrm{C}$ for $1 \mathrm{~h}$, followed by $1 \mathrm{~mL}$ of $30 \%(v / v) \mathrm{H}_{2} \mathrm{O}_{2}$ and diluted with Milli-Q water to get a total volume of $10 \mathrm{~mL}$. For $\mathrm{K}^{+}$analysis, samples were further diluted 10 times with $6 \%(v / v) \mathrm{HNO}_{3}$. For $\mathrm{Cs}^{+}$analysis, $0.1 \%(w / v) \mathrm{KCl}$ was added to each sample and standard solution to prevent ionization of $\mathrm{Cs}^{+}$, according to the manufacturer's instructions 
(PerkinElmer, Waltham, MA, USA). $\mathrm{K}^{+}$and $\mathrm{Cs}^{+}$contents were measured on a flame atomic absorption spectrometer AAnalyst 200 (PerkinElmer). Concentrations were calculated against each standard curve, and one-way ANOVA with Bonferroni's multiple comparison posttest $(p<0.05)$ was performed using Prism to determine the statistical significance.

\section{4. qRT-PCR Analysis}

Seedlings grown for 7 days (for HAK5 expression) or 11 days (for $V S P 2$ and PDF1.2 expression) were flash-frozen in liquid $\mathrm{N}_{2}$ and ground using a mixer mill. Total RNA was extracted, treated with DNaseI (Invitrogen, Carlsbad, CA, USA) and synthesized into cDNA using SuperScript III (Invitrogen). Quantitative real-time reverse transcription-PCR (qRT-PCR) was performed using THUNDERBIRD SYBR qPCR mix (TOYOBO, Osaka, Japan) and a Mx3000P qPCR system (Agilent Technologies, Santa Clara, CA, USA). The amplification conditions were $95{ }^{\circ} \mathrm{C}$ for $15 \mathrm{~s}$ and $60{ }^{\circ} \mathrm{C}$ for $30 \mathrm{~s}$. The cycle was repeated 40 times, preceded by $95{ }^{\circ} \mathrm{C}$ for $1 \mathrm{~min}$ and followed by a dissociation program to create melting curves. Three technical replicates for each sample were run. The $\beta$-tubulin gene (TUB2) was used as a reference gene. The primers used were as follows: HAK5 forward 5'-CGAGACGGACAAAGAAGAGGAACC and reverse 5'-CACGACCCTTCCCGACCTAATCT [49]; VSP2 forward 5'-CCTAAAGAACGACACCGTCA and reverse 5'-TCGGTCTTCTCTGTTCCGTA [54]; PDF1.2 forward 5'-TTGCTGCTTTCGACGCA and reverse TGTCCCACTTGGCTTCTCG [51]; and TUB2 forward 5'-GCCAATCCGGTGCTGGTAACA and reverse 5'-CATACCAGATCCAGTTCCTCCTCCC [49]. One-way ANOVA with Bonferroni's multiple comparison posttest $(p<0.05)$ was performed using Prism to determine the statistical significance.

\subsection{Luciferase Imaging}

HAK5promoter::LUC grown for 11 days were sprayed with luciferin (Duchefa Biochemie, Haarlem, The Netherlands) and kept in the dark for a few minutes prior to imaging. NightSHADE LB 985 (Berthold, Bad Wildbad, Germany) was used to image luciferase chemiluminescence.

\section{Conclusions}

In this study, we have determined that JA signaling is involved in $\mathrm{Cs}^{+}$perception in terms of root growth inhibition, but not in uptake of $\mathrm{K}^{+}$and $\mathrm{Cs}^{+}$. This growth inhibition by $\mathrm{Cs}^{+}$occurs presumably through biosynthesis of JAs and consequent stimulation of the downstream JA signaling pathway. In parallel, $\mathrm{Cs}^{+}$induces expression of a high-affinity $\mathrm{K}^{+}$transporter gene, HAK5, under the $\mathrm{K}^{+}$sufficient condition in a JA signaling-independent manner. However, exogenous application of MeJA inhibits $\mathrm{Cs}^{+}$-induced expression of $H A K 5$, suggesting a complicated "fine-tuning" regulation of $\mathrm{Cs}^{+}$response in plants.

\section{Acknowledgments}

Many thanks to Prof. John Turner (University of East Anglia) for providing coil-16 seeds, Prof. Tatsuo Kakimoto (Osaka University) for ipt 1,3,5,7 and ahk2;3 seeds, Prof. Chi-Kuang Wen (Shanghai Institute for Biological Science, Chinese Academy of Science) for ers 1-1 seeds, Dr. Daniel Schachtman (Donald 
Danforth Plant Science Center) for aux 1-7 seeds and Prof. Nicholas Harberd (University of Oxford) for rga-24;gai-t6 seeds. This work was supported by funding from RIKEN and the Ministry of Agriculture, Forestry and Fisheries of Japan (I2012101).

\section{Conflict of Interest}

The authors declare no conflict of interest.

\section{References}

1. White, P.J.; Broadley, M.R. Mechanisms of caesium uptake by plants. New Phytol. 2000, 147, 241-256.

2. Lasat, M.M.; Norvell, W.A.; Kochian, L.V. Potential for phytoextraction of ${ }^{137}$ Cs from a contaminated soil. Plant Soil 1997, 195, 99-106.

3. Entry, J.A.; Vance, N.C.; Hamilton, M.A.; Zabowski, D.; Watrud, L.S.; Adriano, D.C. Phytoremediation of soil contaminated with low concentrations of radionuclides. Water Air Soil Poll. 1996, 88, 167-176.

4. Collander, R. Selective absorption of cations by higher plants. Plant Physiol. 1941, 16, 691-720.

5. Kanter, U.; Hauser, A.; Michalke, B.; Draxl, S.; Schaffner, A.R. Caesium and strontium accumulation in shoots of Arabidopsis thaliana: Genetic and physiological aspects. J. Exp. Bot. 2010, 61, 3995-4009.

6. Leng, Q.; Mercier, R.W.; Hua, B.G.; Fromm, H.; Berkowitz, G.A. Electrophysiological analysis of cloned cyclic nucleotide-gated ion channels. Plant Physiol. 2002, 128, 400-410.

7. Balague, C.; Lin, B.Q.; Alcon, C.; Flottes, G.; Malmstrom, S.; Kohler, C.; Neuhaus, G.; Pelletier, G.; Gaymard, F.; Roby, D. HLM1, an essential signaling component in the hypersensitive response, is a member of the cyclic nucleotide-gated channel ion channel family. Plant Cell 2003, 15, 365-379.

8. Li, X.L.; Borsics, T.; Harrington, H.M.; Christopher, D.A. Arabidopsis AtCNGC10 rescues potassium channel mutants of E. coli, yeast and Arabidopsis and is regulated by calcium/calmodulin and cyclic GMP in E. coli. Funct. Plant Biol. 2005, 32, 643-653.

9. Schachtman, D.P.; Schroeder, J.I.; Lucas, W.J.; Anderson, J.A.; Gaber, R.F. Expression of an inward-rectifying potassium channel by the Arabidopsis KAT1 cDNA. Science 1992, 258, 1654-1658.

10. Basset, M.; Conejero, G.; Lepetit, M.; Fourcroy, P.; Sentenac, H. Organization and expression of the gene coding for the potassium transport system AKT1 of Arabidopsis thaliana. Plant Mol. Biol. 1995, 29, 947-958.

11. Broadley, M.R.; Escobar-Gutierrez, A.J.; Bowen, H.C.; Willey, N.J.; White, P.J. Influx and accumulation of $\mathrm{Cs}^{+}$by the akt1 mutant of Arabidopsis thaliana (L.) Heynh. lacking a dominant $\mathrm{K}^{+}$transport system. J. Exp. Bot. 2001, 52, 839-844.

12. Qi, Z.; Hampton, C.R.; Shin, R.; Barkla, B.J.; White, P.J.; Schachtman, D.P. The high affinity K transporter AtHAK5 plays a physiological role in planta at very low $\mathrm{K}^{+}$concentrations and provides a caesium uptake pathway in Arabidopsis. J. Exp. Bot. 2008, 59, 595-607.

13. Kim, E.J.; Kwak, J.M.; Uozumi, N.; Schroeder, J.I. AtKUP1: An Arabidopsis gene encoding high-affinity potassium transport activity. Plant Cell 1998, 10, 51-62. 
14. Kobayashi, D.; Uozumi, N.; Hisamatsu, S.; Yamagami, M. AtKUP/HAK/KT9, a $\mathrm{K}^{+}$transporter from Arabidopsis thaliana, mediates $\mathrm{Cs}^{+}$uptake in Escherichia coli. Biosci. Biotechnol. Biochem. 2010, 74, 203-205.

15. Jung, J.Y.; Shin, R.; Schachtman, D.P. Ethylene mediates response and tolerance to potassium deprivation in Arabidopsis. Plant Cell 2009, 21, 607-621.

16. Armengaud, P.; Breitling, R.; Amtmann, A. The potassium-dependent transcriptome of Arabidopsis reveals a prominent role of jasmonic acid in nutrient signaling. Plant Physiol. 2004, 136, 2556-2576.

17. Armengaud, P.; Breitling, R.; Amtmann, A. Coronatine-insensitive 1 (COI1) mediates transcriptional responses of Arabidopsis thaliana to external potassium supply. Mol. Plant 2010, 3, 390-405.

18. Troufflard, S.; Mullen, W.; Larson, T.R.; Graham, I.A.; Crozier, A.; Amtmann, A.; Armengaud, P. Potassium deficiency induces the biosynthesis of oxylipins and glucosinolates in Arabidopsis thaliana. BMC Plant Biol. 2010, 10, 172, doi:10.1186/1471-2229-10-172.

19. Nam, Y.J.; Tran, L.S.P.; Kojima, M.; Sakakibara, H.; Nishiyama, R.; Shin, R. Regulatory roles of cytokinins and cytokinin signaling in response to potassium deficiency in Arabidopsis. PLoS One 2012, 7, e47797, doi:10.1371/journal.pone.0047797.

20. Shin, R.; Burch, A.Y.; Huppert, K.A.; Tiwari, S.B.; Murphy, A.S.; Guilfoyle, T.J.; Schachtman, D.P. The Arabidopsis transcription factor MYB77 modulates auxin signal transduction. Plant Cell 2007, 19, 2440-2453.

21. Wasternack, C. Jasmonates: An update on biosynthesis, signal transduction and action in plant stress response, growth and development. Ann. Bot. 2007, 100, 681-697.

22. Laudert, D.; Pfannschmidt, U.; Lottspeich, F.; Hollander-Czytko, H.; Weiler, E.W. Cloning, molecular and functional characterization of Arabidopsis thaliana allene oxide synthase (CYP 74), the first enzyme of the octadecanoid pathway to jasmonates. Plant Mol. Biol. 1996, 31, 323-335.

23. Chini, A.; Fonseca, S.; Fernandez, G.; Adie, B.; Chico, J.M.; Lorenzo, O.; Garcia-Casado, G.; Lopez-Vidriero, I.; Lozano, F.M.; Ponce, M.R.; et al. The JAZ family of repressors is the missing link in jasmonate signaling. Nature 2007, 448, 666-671.

24. Thines, B.; Katsir, L.; Melotto, M.; Niu, Y.; Mandaokar, A.; Liu, G.H.; Nomura, K.; He, S.Y.; Howe, G.A.; Browse, J. JAZ repressor proteins are targets of the $\mathrm{SCF}^{\mathrm{COI} 1}$ complex during jasmonate signaling. Nature 2007, 448, 661-665.

25. Yan, J.B.; Zhang, C.; Gu, M.; Bai, Z.Y.; Zhang, W.G.; Qi, T.C.; Cheng, Z.W.; Peng, W.; Luo, H.B.; Nan, F.J.; et al. The Arabidopsis CORONATINE INSENSITIVE1 protein is a jasmonate receptor. Plant Cell 2009, 21, 2220-2236.

26. Sheard, L.B.; Tan, X.; Mao, H.B.; Withers, J.; Ben-Nissan, G.; Hinds, T.R.; Kobayashi, Y.; Hsu, F.F.; Sharon, M.; Browse, J.; et al. Jasmonate perception by inositol-phosphate-potentiated COI1-JAZ co-receptor. Nature 2010, 468, 400-405.

27. Xie, D.X.; Feys, B.F.; James, S.; Nieto-Rostro, M.; Turner, J.G. COI1: An Arabidopsis gene required for jasmonate-regulated defense and fertility. Science 1998, 280, 1091-1094.

28. Feys, B.J.F.; Benedetti, C.E.; Penfold, C.N.; Turner, J.G. Arabidopsis mutants selected for resistance to the phytotoxin coronatine are male-sterile, insensitive to methyl jasmonate, and resistant to a bacterial pathogen. Plant Cell 1994, 6, 751-759. 
29. Ellis, C.; Turner, J.G. A conditionally fertile coil allele indicates cross-talk between plant hormone signaling pathways in Arabidopsis thaliana seeds and young seedlings. Planta 2002, 215, 549-556.

30. Park, J.H.; Halitschke, R.; Kim, H.B.; Baldwin, I.T.; Feldmann, K.A.; Feyereisen, R. A knock-out mutation in allene oxide synthase results in male sterility and defective wound signal transduction in Arabidopsis due to a block in jasmonic acid biosynthesis. Plant J. 2002, 31, 1-12.

31. von Malek, B.; van der Graaff, E.; Schneitz, K.; Keller, B. The Arabidopsis male-sterile mutant dde2-2 is defective in the ALLENE OXIDE SYNTHASE gene encoding one of the key enzymes of the jasmonic acid biosynthesis pathway. Planta 2002, 216, 187-192.

32. Staswick, P.E.; Su, W.P.; Howell, S.H. Methyl jasmonate inhibition of root growth and induction of a leaf protein are decreased in an Arabidopsis thaliana mutant. Proc. Natl. Acad. Sci. USA. 1992, 89, 6837-6840.

33. Staswick, P.E.; Tiryaki, I.; Rowe, M.L. Jasmonate response locus JARl and several related Arabidopsis genes encode enzymes of the firefly luciferase superfamily that show activity on jasmonic, salicylic, and indole-3-acetic acids in an assay for adenylation. Plant Cell 2002, 14, $1405-1415$.

34. Pickett, F.B.; Wilson, A.K.; Estelle, M. The auxl mutation of Arabidopsis confers both auxin and ethylene resistance. Plant Physiol. 1990, 94, 1462-1466.

35. Miyawaki, K.; Tarkowski, P.; Matsumoto-Kitano, M.; Kato, T.; Sato, S.; Tarkowska, D.; Tabata, S.; Sandberg, G.; Kakimoto, T. Roles of Arabidopsis ATP/ADP isopentenyltransferases and tRNA isopentenyltransferases in cytokinin biosynthesis. Proc. Natl. Acad. Sci. USA. 2006, 103, 16598-16603.

36. Higuchi, M.; Pischke, M.S.; Mahonen, A.P.; Miyawaki, K.; Hashimoto, Y.; Seki, M.; Kobayashi, M.; Shinozaki, K.; Kato, T.; Tabata, S.; et al. In planta functions of the Arabidopsis cytokinin receptor family. Proc. Natl. Acad. Sci. USA. 2004, 101, 8821-8826.

37. Guzman, P.; Ecker, J.R. Exploiting the triple response of Arabidopsis to identify ethylene-related mutants. Plant Cell 1990, 2, 513-523.

38. Hua, J.; Chang, C.; Sun, Q.; Meyerowitz, E.M. Ethylene insensitivity conferred by Arabidopsis ERS gene. Science 1995, 269, 1712-1714.

39. Dill, A.; Sun, T.P. Synergistic derepression of gibberellin signaling by removing RGA and GAI function in Arabidopsis thaliana. Genetics 2001, 159, 777-785.

40. Penninckx, I.A.M.A.; Thomma, B.P.H.J.; Buchala, A.; Metraux, J.P.; Broekaert, W.F. Concomitant activation of jasmonate and ethylene response pathways is required for induction of a plant defensin gene in Arabidopsis. Plant Cell 1998, 10, 2103-2113.

41. Benedetti, C.E.; Xie, D.X.; Turner, J.G. COI1-dependent expression of an Arabidopsis vegetative storage protein in flowers and siliques and in response to coronatine or methyl jasmonate. Plant Physiol. 1995, 109, 567-572.

42. Berger, S.; Bell, E.; Sadka, A.; Mullet, J.E. Arabidopsis thaliana Atvsp is homologous to soybean $V s p A$ and $V s p B$, genes encoding vegetative storage protein acid phosphatases, and is regulated similarly by methyl jasmonate, wounding, sugars, light and phosphate. Plant Mol. Biol. 1995, 27, 933-942. 
43. Li, Y.J.; Heaton, A.C.P.; Carreira, L.; Meagher, R.B. Enhanced tolerance to and accumulation of mercury, but not arsenic, in plants overexpressing two enzymes required for thiol peptide synthesis. Physiol. Plant. 2006, 128, 48-57.

44. Li, Y.J.; Dankher, O.P.; Carreira, L.; Smith, A.P.; Meagher, R.B. The shoot-specific expression of g-glutamylcysteine synthetase directs the long-distance transport of thiol-peptides to roots conferring tolerance to mercury and arsenic. Plant Physiol. 2006, 141, 288-298.

45. Marmiroli, M.; Visioli, G.; Antonioli, G.; Maestri, E.; Marmiroli, N. Integration of XAS techniques and genetic methodologies to explore Cs-tolerance in Arabidopsis. Biochimie 2009, 91, 180-191.

46. Hampton, C.R.; Bowen, H.C.; Broadley, M.R.; Hammond, J.P.; Mead, A.; Payne, K.A.; Pritchard, J.; White, P.J. Cesium toxicity in Arabidopsis. Plant Physiol. 2004, 136, 3824-3837.

47. Hagiwara, S.; Miyazaki, S.; Rosenthal, N.P. Potassium current and effect of cesium on this current during anomalous rectification of egg cell membrane of a starfish. J. Gen. Physiol. 1976, 67, 621-638.

48. Rubio, F.; Santa-Maria, G.E.; Rodriguez-Navarro, A. Cloning of Arabidopsis and barley cDNAs encoding HAK potassium transporters in root and shoot cells. Physiol. Plant. 2000, 109, 34-43.

49. Ahn, S.J.; Shin, R.; Schachtman, D.P. Expression of $K T / K U P$ genes in Arabidopsis and the role of root hairs in $\mathrm{K}^{+}$uptake. Plant Physiol. 2004, 134, 1135-1145.

50. Kim, M.J.; Ruzicka, D.; Shin, R.; Schachtman, D.P. The Arabidopsis AP2/ERF transcription factor RAP2.11 modulates plant response to low-potassium conditions. Mol. Plant 2012, 5, 1042-1057.

51. Brown, R.L.; Kazan, K.; McGrath, K.C.; Maclean, D.J.; Manners, J.M. A role for the GCC-box in jasmonate-mediated activation of the PDF1.2 gene of Arabidopsis. Plant Physiol. 2003, 132, $1020-1032$.

52. Lorenzo, O.; Piqueras, R.; Sanchez-Serrano, J.J.; Solano, R. ETHYLENE RESPONSE FACTOR1 integrates signals from ethylene and jasmonate pathways in plant defense. Plant Cell 2003, 15, $165-178$.

53. Zarei, A.; Korbes, A.P.; Younessi, P.; Montiel, G.; Champion, A.; Memelink, J. Two GCC boxes and AP2/ERF-domain transcription factor ORA59 in jasmonate/ethylene-mediated activation of the PDF1.2 promoter in Arabidopsis. Plant Mol. Biol. 2011, 75, 321-331.

54. Dombrecht, B.; Xue, G.P.; Sprague, S.J.; Kirkegaard, J.A.; Ross, J.J.; Reid, J.B.; Fitt, G.P.; Sewelam, N.; Schenk, P.M.; Manners, J.M.; Kazan, K. MYC2 differentially modulates diverse jasmonate-dependent functions in Arabidopsis. Plant Cell 2007, 19, 2225-2245.

(C) 2013 by the authors; licensee MDPI, Basel, Switzerland. This article is an open access article distributed under the terms and conditions of the Creative Commons Attribution license (http://creativecommons.org/licenses/by/3.0/). 